\title{
PSO-Based PI Controller for Shunt APF in Distribution Network of Multi Harmonic Sources
}

\author{
Wael M. Elmamlouk \\ Shaker Consultancy Group, Cairo, Egypt \\ E-mail:welmamlouk@ieee.org
}

\author{
Hossam E Mostafa \\ Electrical Department, Faculty of Industrial Education, Suez University, Suez, Egypt \\ E-mail: hossam.mostafa@ieee.org
}

\author{
Metwally A. E-Sharkawy \\ Department of Electrical Power and Machines, Faculty of Engineering, Ain Shams University, Cairo, Egypt \\ E-mail: masharkawy@yahoo.com
}

\begin{abstract}
PI controller tuning with the as sumption of linear PWM model leads to unsatisfactory results under varying operating conditions. Optimal tuning of PI gains is required to get the best response of PI controllers. This paper presents a new method for harmonic suppression using particle swarm optimization (PSO) based PI controller (PSOPI) to estimate an efficient shunt active power filter (SAPF). The proposed filter is tested on a 13 bus industrial distribution system. The study system with the 18 study cases are simulated through MATLAB Simulink with different loading condition and single and multi harmonic sources. The results of applying the PIPSO controller are compared with those out of a double proportional controller (DPC). The obtained results ensure the effectiveness of the proposed filter and its superiority in reducing harmonics.
\end{abstract}

Index Terms - Active Power Filter, PSO A lgorith m, PI Controller, Harmonics Suppression, Power Quality

\section{Introduction}

The evolution of the semiconductor switches technology; power electronics, converters, measurement strategies and control have been allowing a broader of the active power filter. One of the cornerstones of the active filter is its control scheme strategy that is implemented in the active filter controller.

There are myriad techniques for the control of the APF inverter. One of these techniques is the multi-loop feedback control, which was originally used in the single-phase uninterruptible power supply (UPS) application [1].

The reference signal of the multi-loop feedback control method could be any type of electric quantity such as voltage, current or power. The useful information carried by the signal is its wave shape rather than the place where it comes from. Considerable efforts have been done in recent years to estimate the harmonic components [2-4].

Reference [2] proposes the use of four adaptive linear neurons (ADALINEs) networks for online extraction of the direct, inverse, and homopolar voltage components from a composite voltage. This neural network approach is based on a new voltage decomposition technique of unbalanced thre hase e-psystems.

An algorithm for harmonic estimation is presented in [3]. It utilizes a particle swarm optimizer with passive congregation (PSOPC) to estimate the harmonic components. Alongside a least-square (LS) method is used to estimate the amplitudes of these components. The PSOPC and LS method are executed alternately to minimize the error between the original signal and the signal reconstructed from the estimated parameters during the estimation process.

A neural network for extracting voltage and current waveforms is presented in [4]. It consists of an input layer with 32 nodes (32 samples), two hidden layers, and one-node output (1 sample) layer. The sampling rate is $960 \mathrm{HZ}$.

The ANN performs a sample by sample investigation of the input samples, the oldest sample is omitted and all remaining samples are displaced once to the neighbor position leaving an empty position to the new sample.

Artificial intelligence is one of the key areas to solve harmonic compensation in distribution system and make control more robust for transient conditions [5-8].

A fuzzy logic controlled shunt Active Power Filter (APF) for the elimination of current harmonics and reactive power compensation of nonlinear load is presented in [5]. The control scheme is based on indirect current control scheme in which only source 
current is sensed for avoiding switching spikes. Three phase voltage and current signal is sensed using two voltage and current sensors..

The application of a novel neuro-fuzzy based control strategy which is used in order to improve the APF dynamics for wide range of variations of load current under various conditions is described in [6]. To improve dynamic behavior of a shunt active power filter and its robustness under range of load variations, instantaneous $\mathrm{p}$-q theory is used with the inclusion of neural network filter for reference current generation and fuzzy logic controller for DC voltage control..

The implementation of Bacterial foraging optimization (BFO) to optimize the proportionalintegral (PI) APF performance for load compensation under distorted supply voltage condition and sudden load fluctuation is proposed in [7].

Reference [8] uses the double proportional feedback control loop APF for uninterruptible power supply (UPS) application. The controller used as a single phase filter for a dedicated harmonic load and with a fixed voltage source.

A developed APF controller scheme based on a double proportional controller (DPC) feedback gains and a single-phase voltage-source half-wave bridge inverter is presented in [9]. In the outer loop, the generated current signal is fed back and compared with its reference. The resulting error signal is multiplied by the first proportional controller gain, and the output is added to the error signal obtained from comparing the inductor feedback voltage with its reference.

The resulting signal is multiplied by the second proportional controller gain in the inner control loop and the output is compared with a fixed switching frequency triangular waveform, which will be passed to the gate drive circuit. The proposed scheme is tested on a 13 bus industrial distribution system.
In this paper, a modification for the control circuit design of the APF proposed by [9] for compensation scheme is presented in this paper. This modification is summarized simply by removing the two proportional controllers from the inner and outer control loops for the voltage and current signals simultaneously and replaced by the PI controller in the inner loop. The feedback signals in this paper are the per-unit values of the voltage and current. The PI gains are estimated using particle swarm optimization (PSO) technique.

The scheme is applied on a 3-phase 13 bus industrial balanced distribution system. The measured voltage total harmonic distortion (THDv\%) and current total harmonic distortion (THDi\%) results are compared with those out of the DPC of [8]. The comparison shows the superiority of the proposed PSOPI controller over the DPC for compensating most of voltage and current harmonics at the chosen point of common coupling (PCC).

This paper is organized as follows: section II describes the proposed APF controller scheme, while section III shows the APF block diagram including the PSOPI controller. In section IV, the component of system under study will be illustrated. Section V shows the parameters of the filter and the 18 study cases that will be applied on the study system to evaluate its performance. Sections VI \& VII will view the simulation results and analysis of the results respectively. Finally, conclusions out of the results will be shown in section VIII.

\section{Proposed APF Scheme}

The proposed topology of the active filter is consists of a single-phase voltage-source half-wave bridge inverter, a second-order low-pass filter with an inner inductor voltage feedback loop and an outer current feedback loop for current compensation as shown in Figure (1).

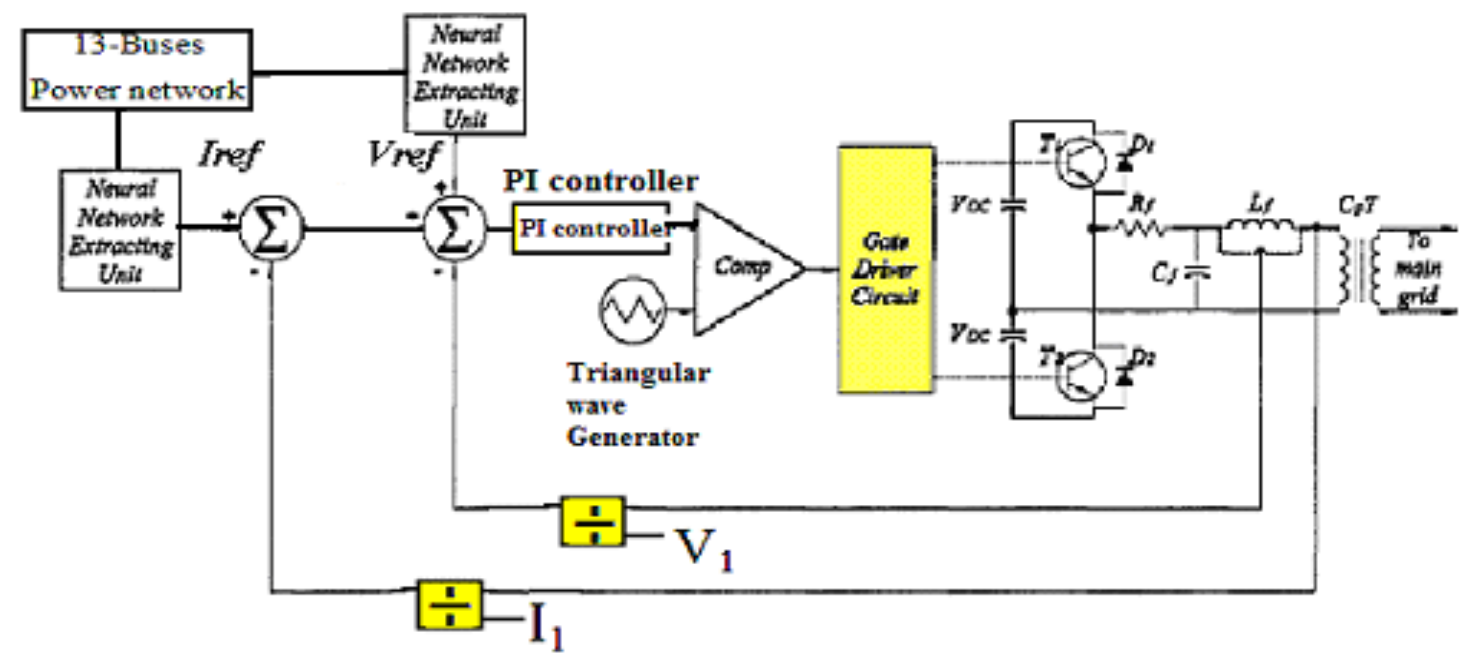

Fig. 1: Block diagram for current compensation scheme based on the inductor voltage with P I controller 
In the outer loop, the generated current signal is fed back and divided by the fundamental current, then compared with its reference. The resulting error signal is added to the error signal obtained from comparing the inductor feedback voltage divided by its fundamental voltage with its reference.

The resulting signal is then processed by the PI controller, which obtained its gains by the PSO in the inner loop, and the output is compared with a fixed switching frequency triangular waveform, which will be passed to the gate drive circuit.

The gate drive circuit for current compensation will produce an optimum switched control signals for the Pulse Width Modulated (PWM) Voltage Source Inverter (VSI) of a number of CSC modules as shown in Fig. 1.

The neural network extracting units used in this study was developed and tested and its accuracy was assured in a previous work of the authors [4].

\section{PSO-Based PI Active Power Filter}

Partic le Swarm Optimization (PSO) [10] has been an increasingly hot topic in the area of computational intelligence. PSO is yet another optimization algorithm that falls under the soft computing umbrella that covers genetic and evolutionary computing algorithms as well. As such, it lends itself as being applicable to a wide variety of optimization problems. One application that PSO has had tremendous success is in the training of Artificial Neural Networks (ANN), a fellow soft computing technique.

\subsection{Particle Swarm Optimization Technique}

Kennedy and Eberhart [11] introduce the PSO concept. PSO is basically developed through simulation of bird flocking in two-dimension space. The position of each particle is represented by XY axis position and the velocity is expressed by $v_{x}$ and $v_{y}$ (the particle velocities in the $\mathrm{x}$ direction and $\mathrm{y}$ direction respectively). Modification of the agent position is realized by the position and velocity information. This modification can be represented by the concept of velocity. Velocity of each agent can be modified by the following equations:

$$
\begin{aligned}
& v_{i, n}^{k+1}=K\left[v_{i, n}^{k}+c_{1} \operatorname{rand}_{1} *\left(\text { pbest }_{i, n}-x_{i, n}^{k}\right)\right. \\
& \left.+c_{2} \operatorname{rand}_{2} *\left(\text { gbest }_{n}-x_{i, n}^{k}\right)\right] \\
& K=\frac{2}{\left|2-\phi-\sqrt{\phi^{2}-4 \phi}\right|}, \\
& \text { and } \phi=c_{1}+c_{2}, \phi>4
\end{aligned}
$$

where,

$\mathrm{K}$ : constriction factor

$v_{i, n}^{k}$ : velocity of agent $\mathrm{i}$ at iteration $\mathrm{k}$ and dimension

$\mathrm{n}$,

$c_{j}$ : weighting factor,

rand $_{j}$ : random number between 0 and 1 ,

$x_{i, n}^{k} \quad$ : current position of agent $\mathrm{i}$ at iteration $\mathrm{k}$ and dimension $\mathrm{n}$,

pbest $_{i, n}$ : pbest of agent $\mathrm{i}$ and dimension $\mathrm{n}$,

gbest $_{n}$ : gbest of the group at dimension $\mathrm{n}$.

The current position (searching point in the solution space) can be modified by the following equation:

$$
x_{i, n}^{k+1}=x_{i, n}^{k}+v_{i, n}^{k+1}
$$

All velocities and positions are represented by vectors in an $\mathrm{n}$ dimensional space (number of space dimensions are the number of parameters to be optimized which are the three for the PID gains).

\subsection{Simulated Control Circuit}

Fig. 2 shows a block diagram for the simulated control circuit of the PI active power filter representing all components of Fig. 1.

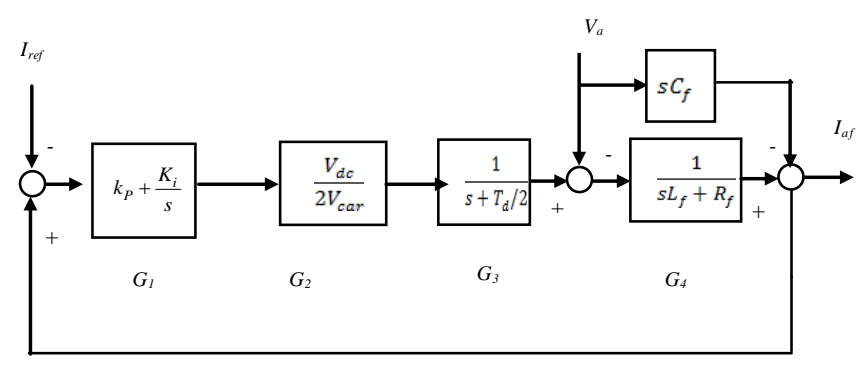

Fig. 2: Block diagram for the control circuit 
where G1 is the transfer function of the PI controller.

G2 is the gain of the PWM converter

G3 is the time delay caused by the PWM inverter

G4 models the delay of the current of the active filter from the output voltage of the active filter.

$$
\begin{array}{ll}
k_{p} & \text { proportional gain } \\
k_{i} & \text { integral gain } \\
V_{d c} & \text { dc bus voltage of the inverter } \\
V_{c a r} & \text { amplitude of carrier waveform } \\
T_{d} & \text { PWM time delay } \\
L_{f} & \text { filter inductance } \\
R_{f} & \text { filter resistance } \\
C_{f} & \text { filter capacitance } \\
I_{r e f} & \text { current harmonic component } \\
I_{a f} & \text { filter line output current waveform } \\
V_{a} & \text { filter line output voltage waveform }
\end{array}
$$

$V_{a}$ can be considered as disturbance, and $I_{r e f}$ denotes the harmonic content of the load current. The transfer function of the block diagram of Figure (2) is as follow:

$$
G(s)=\frac{V_{d c}\left(k_{p} s+k_{i}\right)}{2 V_{c a r} L_{f} s^{2}+\left(2 V_{c a r} R_{f}+V_{d c} k_{p}\right) s+k_{i}}
$$

\subsection{Objective Function}

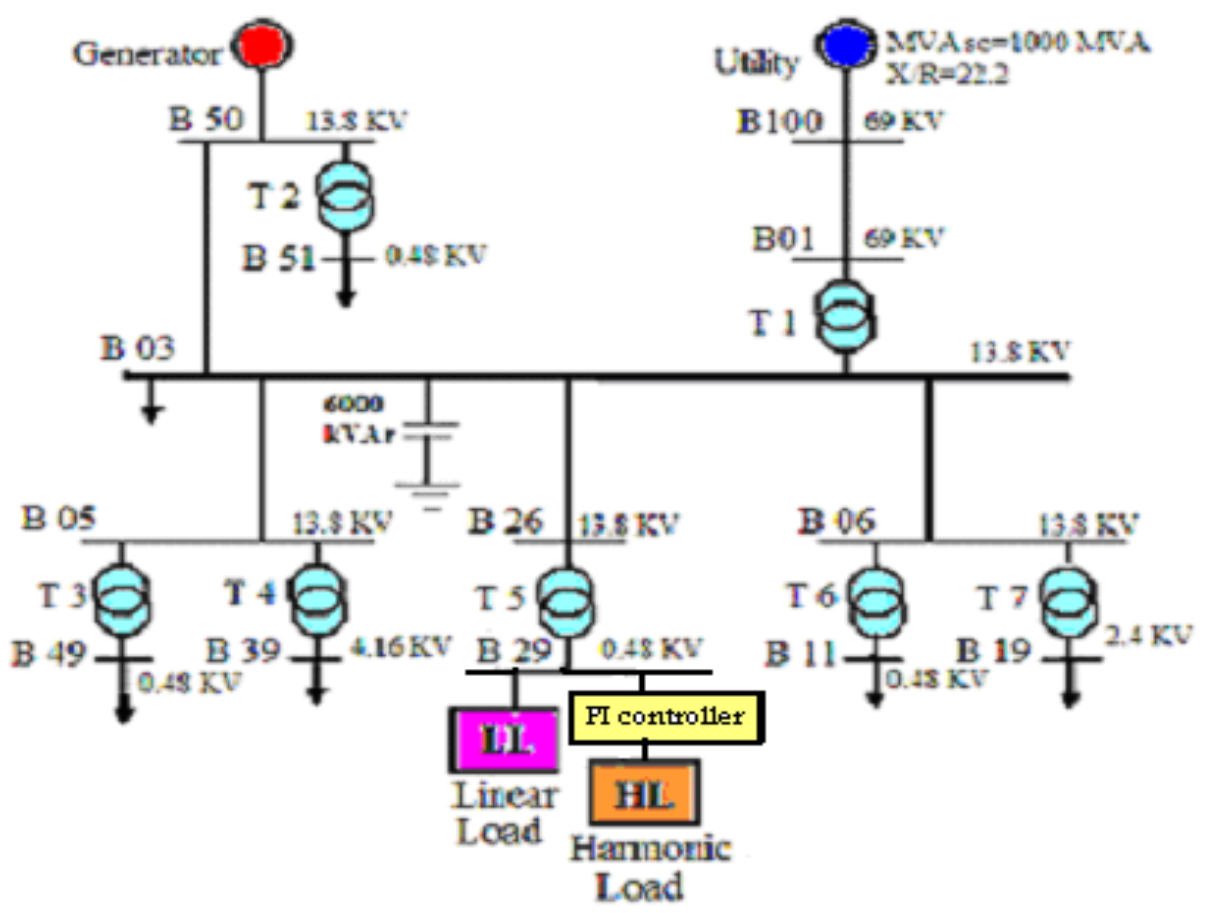

To increase the system damping, the eigenvaluebased objective function is considered as follows:

$$
J=\max \left\{\begin{array}{l}
\operatorname{Real}\left(\lambda_{\mathrm{i}}\right): \\
\lambda_{\mathrm{i}} \in \text { electromechanical modes }
\end{array}\right\}
$$

where Real $\left(\lambda_{\mathrm{i}}\right)$ is the real part of the $\mathrm{i}^{\text {th }}$ electromechanical mode eigenvalue of the $A$ matrix. In the optimization process, it is aimed to minimize $J$ in order to shift the poorly damped eigenvalues to the left in s-plane.

The proposed approach employs PSO to solve this optimization problem and search for an optimal set of PI gains. MATLAB files for the PSO have been developed in [12]. It is modified and employed to get the optimal values of the PI gains. In addition to the main PSO program, additional programs are designed to get the state-space representation of the system.

\section{Study System}

The proposed scheme is applied on a medium-sized 13 bus Balanced Industrial Distribution test system of an industrial plant [13]. A single-line diagram of this system is shown in Fig. 3. The plant is fed from a utility supply at $69 \mathrm{kV}$ at bus $\mathrm{B} 100$ and the local plant distribution system operates at $13.8 \mathrm{kV}$. Due to the balanced nature of this system, only positive sequence data is provided. The assumptions used to conduct a harmonic analysis of the example industrial system include the following [14]:

Fig. 3: Single line diagram of 13-Bus Industrial Distribution System 
- Capacitance of the short overhead line and all cables are neglected.

- System equivalent impedance is determined from the fault MVA and X/R ratio at the utility connection point. These values are $1000 \mathrm{MVA}$ and 22.2 p.u. respectively.

- The local generator is represented as a simple Thevenin equivalent. The internal voltage, determined from the converged power flow solution, is $13.98 \angle-1.52^{\circ} \mathrm{kV}$. The equivalent impedance is the sub-transient impedance, which is $(0.0366+$ j1.3651) $\Omega$.

- The plant power factor correction capacitors are rated at $6000 \mathrm{kVAr}$. As is typically done, leakage and series resistance of the bank are neglected in this study.

- All loads are modeled as series RL circuits. This approach is taken instead of parallel RL modeling to get more accurate representation of induction motors without extremely detailed motor models.

- Frequency dependence of model resistance is neglected.

- Transformer magnetizing branch effects are neglected.
- Transformer winding losses increase as a function of frequency is also neglected.

- The generator shown in Fig. (3) is $60 \mathrm{~Hz}$ diesel type.

The source of harmonics is the Adjustable Speed Drive (ASD) connected to bus 29.

This test system is simulated in [15] using the MATLAB-Simu link program as shown in Fig. 4 and the PCC is chosen to be at the secondary side of the transformer T5 (bus 29). The voltage and current waveforms at this bus are monitored and the THD is measured to protect the linear load (LL) connected to bus 29 from harmonics generated by the harmonic generating load (HL) connected to the same bus and also to reduce the harmonic distortion at all buses of the system according to the limits specified by the IEEE 519-1992 [13]. The harmonic generating load connected to bus 49 in the original system is replaced here by an equivalent linear load. It was found that the harmonic source at bus 49 has a very s mall effect on the voltage and current waveform at bus 29 .

This small effect because Bus 29 is not on the direction of the current harmonics flow from the supply to bus 49 .

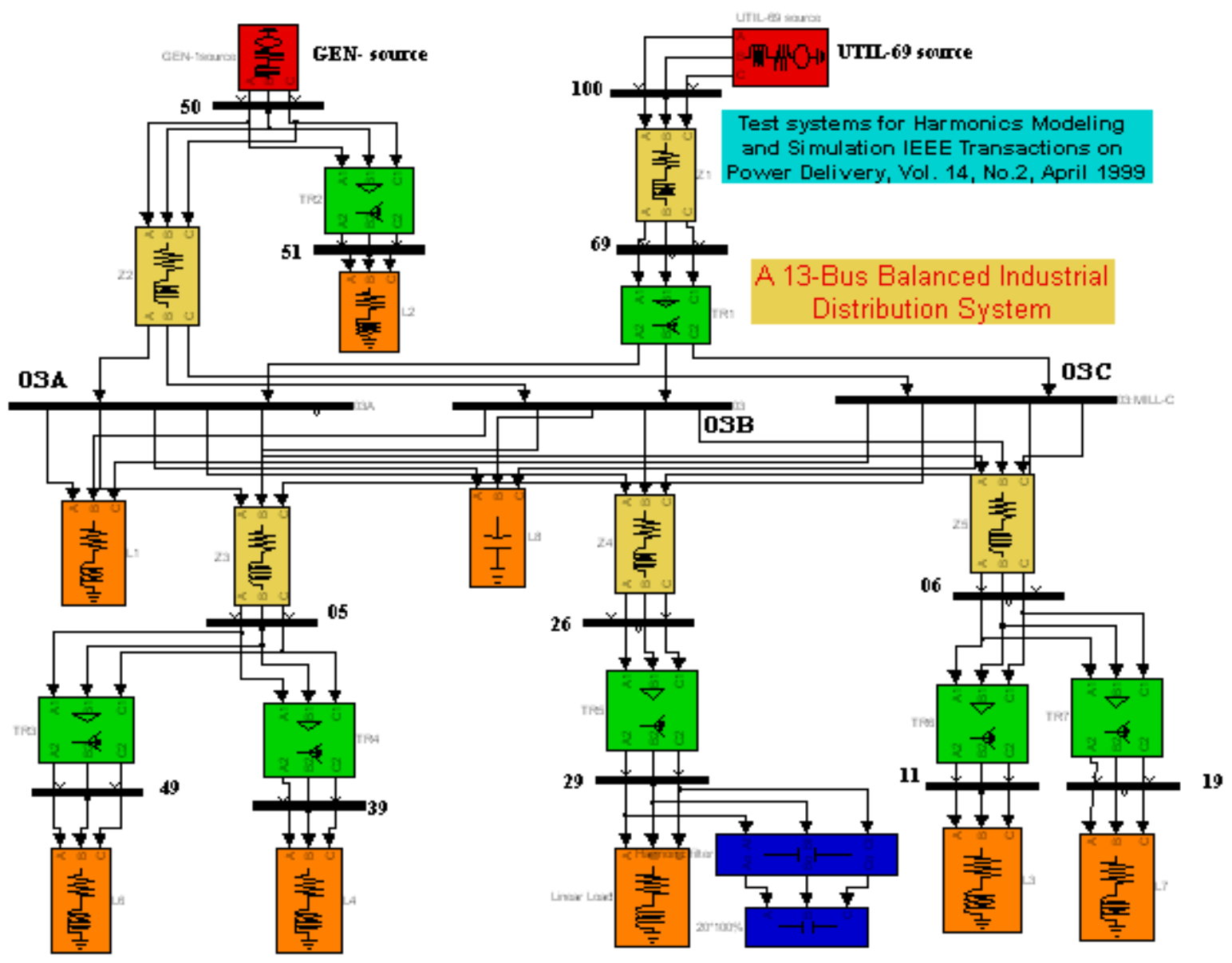

Fig. 4: Simulation of the test system on the Matlab program 
The ASD used as a harmonic source consists of set of $22 \mathrm{~kW}$ three phase induction motors connected in parallel and each of them is served by $22 \mathrm{~kW}$ pulse width modulated (PWM) inverter. The ASD is modeled by a harmonic current source. Each harmonic component is modeled by a current source with a frequency multiple integer of the fundamental frequency. The magnitude and phase angle of the harmonic component are related to the fundamental current [16].

\section{Performance Evaluation of the Proposed PSOPI Controller}

The Multi-loop feedback controller parameters presented here in table (1) have been used with the particle swarm optimization technique for the estimation of the PI-controller gains.

The obtained values of the PI gains using PSO technique are:

$$
k_{p}=0.843, k_{i}=176 .
$$

The obtained gains used with the new proposed PIcontroller filter replacing the two proportional controls presented in [last paper] and also using the per unit values of the reference voltage and currents instead of the physical quantities in the reference and feedback loops.

Table 1: Parameter Of A Current Compen sation Filter Equipped With A ML_PSOPI Controller

\begin{tabular}{|c|cc|}
\hline AC Source Voltage, $\mathrm{V}_{\mathrm{S}}$ & 480 & $\mathrm{~V}$ \\
\hline DC Inverter Voltage, $\mathrm{V}_{\mathrm{DC}}$ & 220 & $\mathrm{~V}$ \\
\hline Fundamental Frequency & 60 & $\mathrm{~Hz}$ \\
\hline Sampling Frequency & $10,000 \quad \mathrm{~Hz}$ \\
\hline PWM Carrier Frequency & $5,000 \quad \mathrm{~Hz}$ \\
\hline Line Resistance, $\mathrm{R}_{\mathrm{S}}$ & $0.1 \quad \Omega$ \\
\hline Line Inductance, $\mathrm{L}_{\mathrm{S}}$ & 1 & $\mathrm{mH}$ \\
\hline Filter Resistance, $\mathrm{R}_{\mathrm{C}}$ & 0.1 & $\Omega$ \\
\hline Filter Inductance, $\mathrm{L}_{\mathrm{C}}$ & 0.1 & $\mathrm{mH}$ \\
\hline Filter Capacitance, $\mathrm{C}_{\mathrm{C}}$ & 4,500 & $\mu \mathrm{F}$ \\
\hline
\end{tabular}

\subsection{Study Cases}

18 different combinations of harmonic load locations and loading levels are chosen to extensively cover the study of the harmonic problem for the system under study. These combinations are shown in table (2).

Table 2: Study Cases for Different Load Combinations

\begin{tabular}{|c|c|c|c|c|c|c|c|c|}
\hline \multirow[b]{2}{*}{ Case } & \multicolumn{2}{|c|}{ Bus 29} & \multicolumn{2}{|c|}{ Bus 51} & \multicolumn{2}{|c|}{ Bus 11} & \multicolumn{2}{|c|}{ Bus 29 LL } \\
\hline & $\begin{array}{l}\text { Total motor } \\
\text { load, kW }\end{array}$ & $\begin{array}{l}\text { ASD load } \\
\text { level \% }\end{array}$ & $\begin{array}{l}\text { Total motor } \\
\text { load, } \mathrm{kW}\end{array}$ & $\begin{array}{l}\text { ASD load } \\
\text { level \% }\end{array}$ & $\begin{array}{l}\text { Total motor } \\
\text { load, kW }\end{array}$ & $\begin{array}{l}\text { ASD load } \\
\text { level \% }\end{array}$ & $\mathbf{k W}$ & $\begin{array}{c}\mathbf{k V A} \\
\mathbf{r}\end{array}$ \\
\hline 1 & 800 & 75 & - & - & 1200 & 50 & 700 & 200 \\
\hline 2 & 800 & 75 & 400 & 100 & 800 & 100 & 600 & 400 \\
\hline 3 & 800 & 50 & 800 & 75 & 800 & 100 & 600 & 600 \\
\hline 4 & $\begin{array}{l}800, \\
600\end{array}$ & 50,100 & - & - & - & - & 200 & 200 \\
\hline 5 & $\begin{array}{l}800 \\
400\end{array}$ & $\begin{array}{l}75, \\
50\end{array}$ & - & - & - & - & 600 & 200 \\
\hline 6 & $\begin{array}{l}800, \\
400, \\
400\end{array}$ & $50,100,75$ & - & - & - & - & 300 & 0 \\
\hline 7 & 600 & 100 & 600 & 100 & 800 & 100 & 600 & 600 \\
\hline 8 & $\begin{array}{l}800 \\
400\end{array}$ & 100,75 & - & - & - & - & 300 & 100 \\
\hline 9 & $\begin{array}{l}400 \\
400, \\
400\end{array}$ & $100,75,50$ & - & - & - & - & 400 & 200 \\
\hline 10 & 1200 & 75 & 800 & 50 & - & - & 400 & 100 \\
\hline 11 & $\begin{array}{l}400 \\
800\end{array}$ & 100,50 & 800 & 50 & - & - & 500 & 200 \\
\hline 12 & 1200 & 50 & - & - & 800 & 50 & 700 & 300 \\
\hline 13 & $\begin{array}{l}400, \\
1200\end{array}$ & 75,50 & - & - & 800 & 50 & 500 & 100 \\
\hline 14 & 400 & 50 & 800 & 75 & 800 & 50 & 1200 & 300 \\
\hline 15 & - & - & 800 & 75 & 1200 & 50 & 1000 & 600 \\
\hline 16 & 1200 & 100 & - & - & - & - & 200 & 100 \\
\hline 17 & 400 & 75 & 400 & 75 & 400 & 75 & 800 & 800 \\
\hline 18 & 800 & 100 & 1200 & 50 & 1200 & 50 & 300 & 300 \\
\hline
\end{tabular}


In the study case \# 1 , for example, motor loads of 800 $\mathrm{kW}$ and $1200 \mathrm{~kW}$ are connected, respectively, to buses 29 and 11 and a linear load of $(700 \mathrm{~kW}+200 \mathrm{kVAr})$ is also connected to bus 29. The ASDs supplying the 800 $\mathrm{kW}$ and $1200 \mathrm{~kW}$ motor loads are run, respectively, at $75 \%$ and $50 \%$ of their nominal capacities.

The study cases in table (1) are chosen to get the maximum possibility for harmonic current circulation. The cases could be divided according to the number, location and loading level of harmonic loads into three main categories as follows:

1- A single ASD, with different ASD and motor loading levels, is connected to some different system buses, one at time, in the study cases \# 4, 5, 6, 8, 9 and 16.

2- Two ASDs are simultaneously connected to two different buses in the study cases \# 1, 10,11, 12 and 13.

3- Three ASDs are Simultaneously connected to three different busses in the study cases \# 2,3,7,14,17, and 18.

\subsection{Applying the ML-ANN on the Test System}

In this stage, two independent ML-ANNs with shift method are used to estimate the fundamental frequency voltage and current components for the industrial distribution system.

The estimated fundamental voltage and current waveforms are subtracted, respectively, from the polluted voltage and current waveforms as shown in fig. 5 and fig. 6. The resulting voltage and current harmonics are used as reference signals for the PSOPI controller in the next stage.
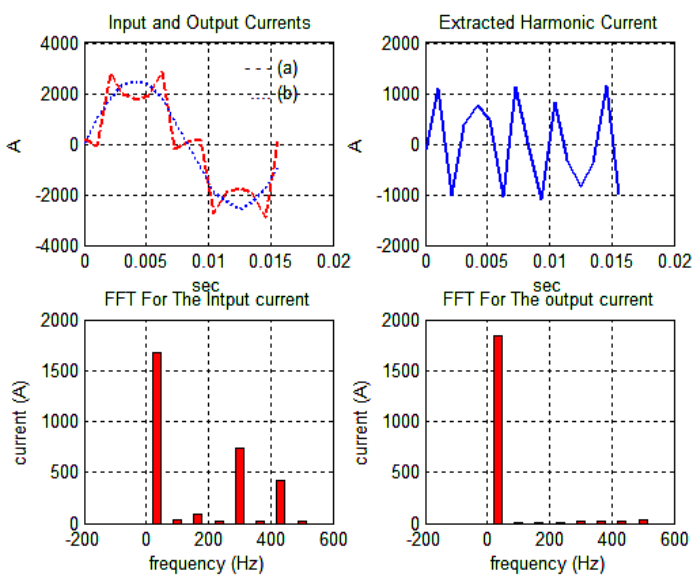

Fig. 5: Current wave forms and Fast Fourier Transform

Fig. 5 shows the distorted input current, the estimated fundamental current wave form and the extracted harmonic contents from the input at bus 29 for case 6 . Also present the Fast Fourier Transform (FFT) decomposition for the distorted input and the estimated output signal at bus 29 for case 6 .
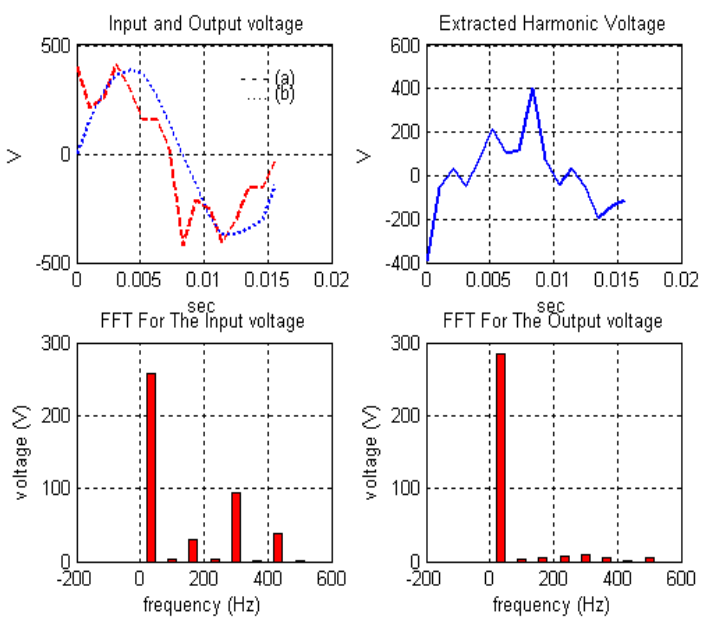

Fig. 6: Voltage wave forms and Fast Fourier Transform

Fig. 6 shows the distorted input voltage, the estimated fundamental voltage wave form and the extracted harmonic contents from the input at bus 29 for case 6. Also present the Fast Fourier Transform (FFT) decomposition for the distorted input and the estimated output signal at bus 29 for case 6 .

\section{Simulation Results}

The performance of the proposed PSOPI control scheme is examined for harmonics control application throughout the 13-bus industrial distribution test system described in details in section IV. The control scheme is tested for 12 cases (cases 7 to 18) since the first 6 cases are used for training the multilayer neural network.

The voltage and current waveforms are monitored at each case, and the current total harmonic distortions at buses 51, 29 and 11 are measured when using the multiloop feedback control scheme with PI-controller based on PSO technique.

\subsection{Detection of Voltage THD at All Buses}

The voltage total harmonic distortion at all the system buses is measured to indicate the effect of the proposed PSO-based filter. Tables ( $3 \& 4$ ) present the THDv\% at all system buses for the different cases after the connection of the ML-PI/PSO filter at bus 29 .

Looking at the obtained results, it is found that the THDv\% at bus 29 is varying from case to case according to harmonic source rating and location in the system. The THDv\% reaches in some cases $8.837 \%$ as in case 18 , which could be seen as the worst case from point of view of the THDv\% at bus 29 . While in other case the THDv\% may reach a very s mall value $(0.952 \%)$ as in case 16. 
Table 3: THDv\% for the Study Cases \#7 to \#12 with the PIC Filter

\begin{tabular}{|c|c|c|c|c|c|c|}
\hline & \multicolumn{7}{|c|}{ THDv \% } \\
\hline Bus & Case 7 & Case 8 & Case 9 & Case 10 & Case 11 & Case 12 \\
\hline $\mathbf{1 0 0}$ & 0.724 & 0.278 & 0.449 & 0.560 & 0.575 & 0.506 \\
\hline $\mathbf{6 9}$ & 1.297 & 0.285 & 0.450 & 0.698 & 0.714 & 0.672 \\
\hline $\mathbf{0 3}$ & 6.728 & 0.443 & 0.526 & 2.659 & 2.690 & 2.834 \\
\hline $\mathbf{5 0}$ & 6.517 & 0.435 & 0.521 & 2.567 & 2.597 & 2.747 \\
\hline $\mathbf{5 1}$ & 11.430 & 0.396 & 0.477 & 8.811 & 8.821 & 2.678 \\
\hline $\mathbf{0 5}$ & 6.727 & 0.443 & 0.526 & 2.658 & 2.690 & 2.834 \\
\hline $\mathbf{4 9}$ & 5.630 & 0.371 & 0.513 & 2.236 & 2.263 & 2.376 \\
\hline $\mathbf{3 9}$ & 6.307 & 0.389 & 0.520 & 2.505 & 2.534 & 2.665 \\
\hline $\mathbf{2 6}$ & 6.729 & 0.444 & 0.526 & 2.659 & 2.690 & 2.834 \\
\hline $\mathbf{0 6}$ & 6.730 & 0.443 & 0.526 & 2.659 & 2.690 & 2.830 \\
\hline $\mathbf{1 1}$ & 13.830 & 0.403 & 0.481 & 2.763 & 2.804 & 8.581 \\
\hline $\mathbf{1 9}$ & 6.348 & 0.390 & 0.521 & 2.520 & 2.549 & 2.677 \\
\hline $\mathbf{2 9}$ & 6.594 & 0.970 & 0.830 & 2.758 & 2.736 & 2.776 \\
\hline
\end{tabular}

Table 4: THDv\% for the Study Cases \#13 to \#18 with the PIC Filter

\begin{tabular}{|c|c|c|c|c|c|c|}
\hline & \multicolumn{7}{|c|}{ THDv \% } \\
\hline Bus & Case 13 & Case 14 & Case 15 & Case 16 & Case 17 & Case 18 \\
\hline $\mathbf{1 0 0}$ & 0.448 & 0.722 & 0.828 & 0.341 & 0.609 & 0.891 \\
\hline $\mathbf{6 9}$ & 0.625 & 1.299 & 1.592 & 0.343 & 0.870 & 1.600 \\
\hline $\mathbf{0 3}$ & 2.760 & 6.735 & 8.468 & 0.483 & 3.905 & 8.311 \\
\hline $\mathbf{5 0}$ & 2.674 & 6.511 & 8.189 & 0.476 & 3.778 & 8.032 \\
\hline $\mathbf{5 1}$ & 2.613 & 12.500 & 13.210 & 0.466 & 6.483 & 14.540 \\
\hline $\mathbf{0 5}$ & 2.760 & 6.734 & 8.467 & 0.483 & 3.905 & 8.310 \\
\hline $\mathbf{4 9}$ & 2.315 & 5.589 & 7.031 & 0.449 & 3.262 & 6.923 \\
\hline $\mathbf{3 9}$ & 2.599 & 6.288 & 7.910 & 0.460 & 3.658 & 7.788 \\
\hline $\mathbf{2 6}$ & 2.760 & 6.734 & 8.468 & 0.484 & 3.905 & 8.313 \\
\hline $\mathbf{0 6}$ & 2.756 & 6.732 & 8.463 & 0.483 & 3.903 & 8.306 \\
\hline $\mathbf{1 1}$ & 8.560 & 10.060 & 14.320 & 0.472 & 6.374 & 14.280 \\
\hline $\mathbf{1 9}$ & 2.611 & 6.323 & 7.954 & 0.461 & 3.558 & 7.831 \\
\hline $\mathbf{2 9}$ & 2.831 & 5.505 & 8.200 & 0.952 & 3.652 & 8.837 \\
\hline
\end{tabular}

\subsection{Detection of Current THD in Lines Feeding Buses 51, $11 \& 29$}

Tables 5 and 6 present the THDi\% found in currents fed to buses 51,11 and 29 for the 12 study cases after connecting the PSO-based PI filter at bus 29. The
THDi\% of harmonic currents circulated in the LL at bus 29 is also given in the same tables. It is found that the THDi\% is varying from case to another, according to harmonic source rating, and from one bus to another, according to the location of the bus in the system.

Table 5: THDi\% in Currents Fed to Buses 51, 11 and 29 with PIC Filter for the Study Cases \#7 to \#12

\begin{tabular}{|c|c|c|c|c|c|c|}
\hline & \multicolumn{7}{|c|}{ THDi \% } \\
\hline Buses & Case 7 & Case 8 & Case 9 & Case 10 & Case 11 & Case 12 \\
\hline 51 & 28.410 & 0.286 & 0.402 & 30.250 & 30.250 & 0.766 \\
\hline 11 & 42.160 & 0.287 & 0.403 & 0.745 & 0.788 & 41.590 \\
\hline 29 & 2.103 & 2.755 & 2.680 & 3.110 & 2.498 & 2.153 \\
\hline $29: \mathrm{LL}$ & 1.571 & 0.571 & 0.524 & 1.497 & 1.144 & 1.077 \\
\hline
\end{tabular}


Table 6: THDi\% in Currents Fed to Buses 51, 11 and 29 with PIC Filter for the Study Cases \#13 to \#18

\begin{tabular}{|c|c|c|c|c|c|c|}
\hline & \multicolumn{7}{|c|}{ THDi \% } \\
\hline Buses & Case 13 & Case 14 & Case 15 & Case 16 & Case 17 & Case 18 \\
\hline 51 & 0.724 & 34.940 & 34.920 & 0.342 & 22.080 & 38.070 \\
\hline 11 & 41.590 & 41.550 & 51.050 & 0.343 & 31.400 & 51.110 \\
\hline 29 & 2.520 & 2.597 & 2.170 & 3.286 & 1.318 & 3.700 \\
\hline $29: \mathrm{LL}$ & 1.710 & 3.048 & 2.820 & 0.517 & 0.962 & 1.989 \\
\hline
\end{tabular}

\subsection{Comparis on of the PSO-based PI Controller and the Two Proportional Controller}

Cases \#16 and \#18 are selected to compare the effectiveness of the two APF controller schemes on harmonics on the 13 bus industrial distribution system. In each case the voltage and current waveforms at bus 29 and the current drawn by the linear load bus 29:LL are monitored. Also at each case the THDv\% at all system buses with the PSOPI filter and with the DPC filter [9] are compared. The same comparison is done for THDi\% at bus 51, 11, 29 and bus 29:LL.

\section{Case 16}

Fig. 7 presents the simulation voltage and current waveforms for the multi-loop feedback control system with the PSOPI filter at bus 29 when applied to the test systemfor case 16 .

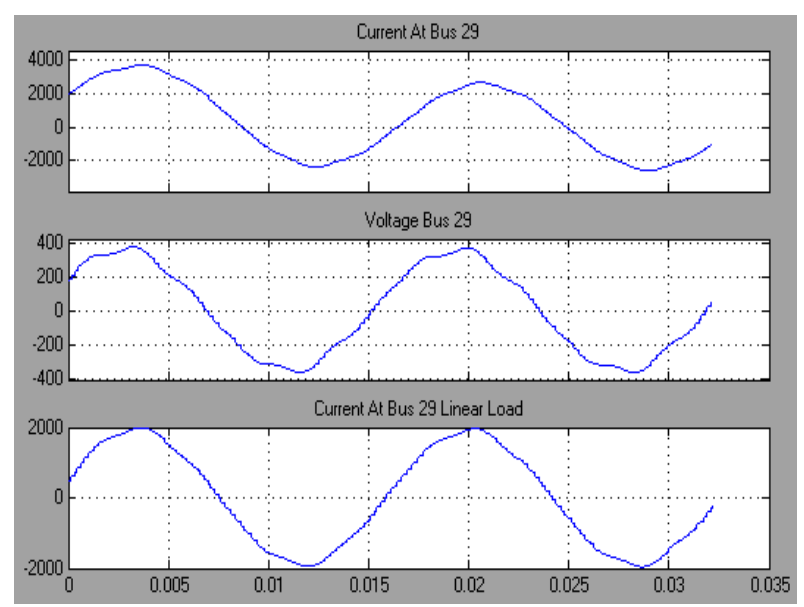

Fig. 7: Voltage and current waveforms at Bus 29 for case 14 with PIC filter

Fig. 8 presents the measured THDv\% at all system buses with the PSOPI filter and with the DPC also Fig. 9 presents the measured THDi\% at bus 51, 11, 29 and 29:LL with the PSOPI filter and without the connection of the filter when applied to the test systemcase 16.

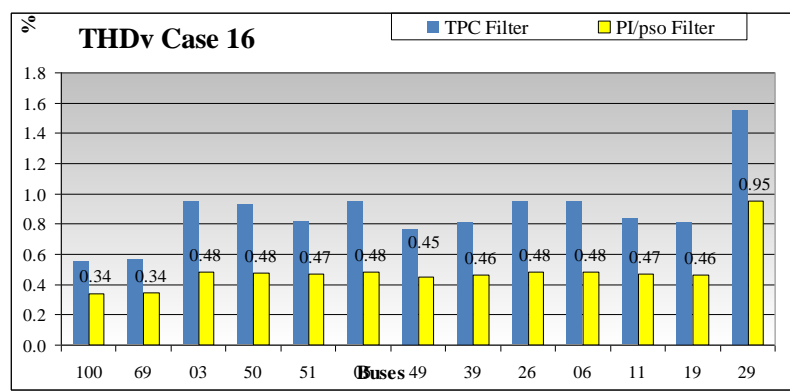

Fig. 8: THDv\% at all system buses for case 16 with PIC and without filter

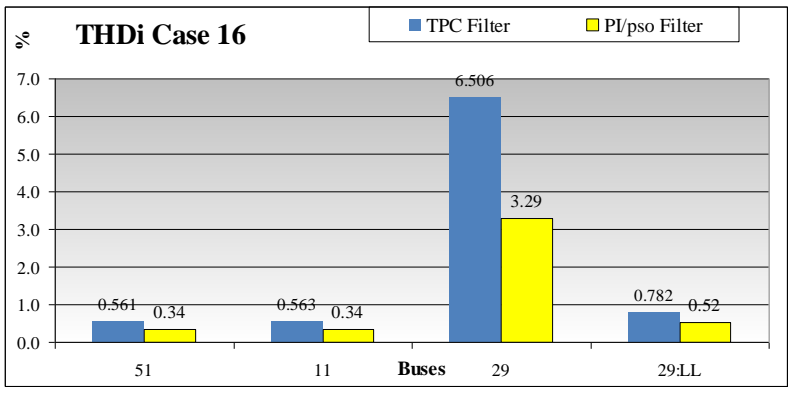

Fig. 9: THDi\% for case 14 with PIC and without filter

\section{Case 18}

Fig. 10 presents the simulation voltage and current waveforms for the multi-loop feedback control system with PSOPI at bus 29 when applied to the test system case 18 .

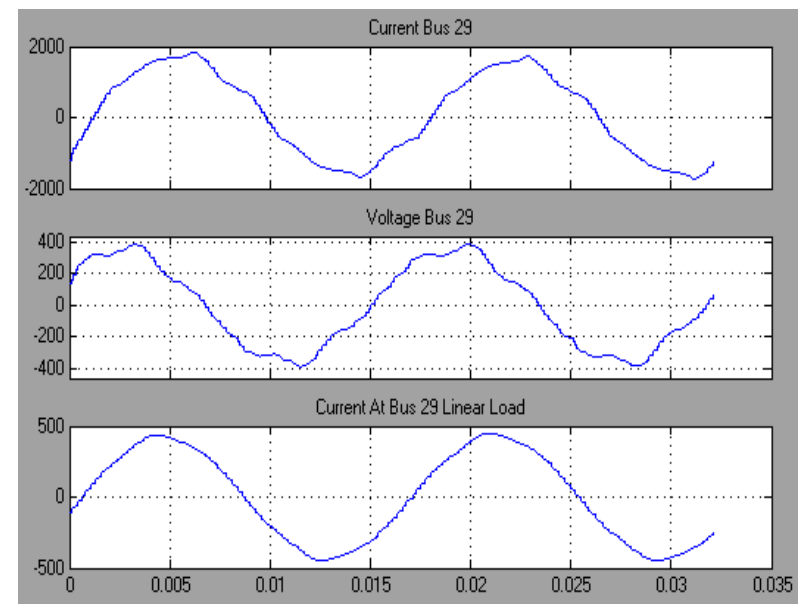

Fig. 10: Voltage and current waveforms at Bus 29 for case 18 with PIC filter 
Fig. 11 presents the measured THDv\% at all system buses with the PSOPI filter and with the DPC filter. Fig. 12 also presents the measured THDi\% at bus $51,11,29$ and 29:LL with the PSOPI filter and with the DPC filter when applied to the test systemcase 18.

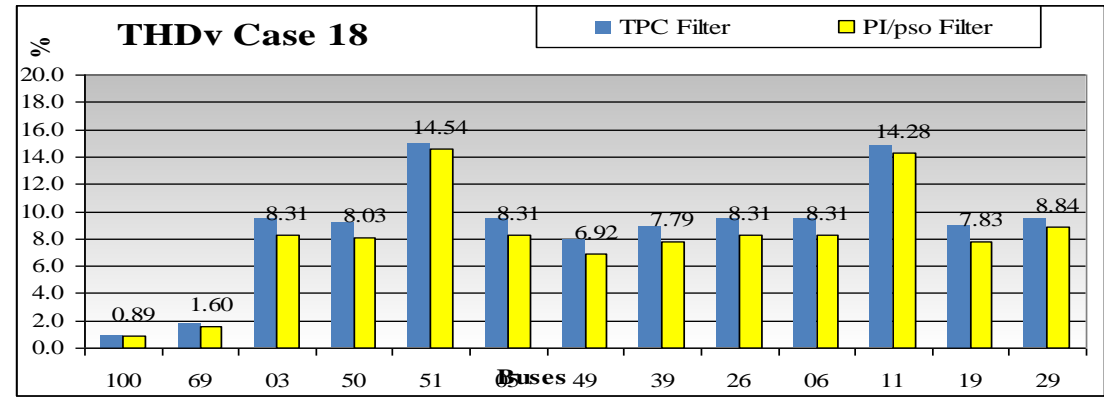

Fig. 11: THDv\% at all system buses for case $18 \mathrm{With}$ PIC and without filter

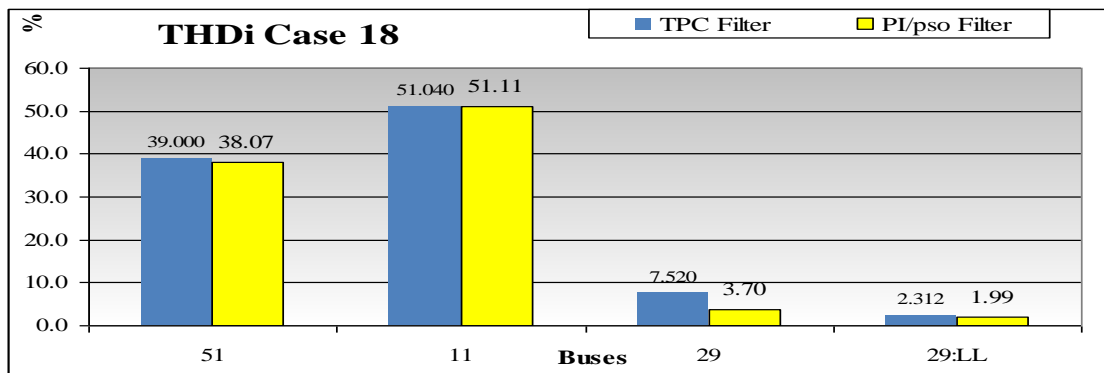

Fig. 12: THDi\% for case 18 with PIC and without filter

Tables (7 \& 8) presenting the percentage improvement in THDv\% and THDi\% respectively, caused by using the POSPI controller compared with that of using the DPC for the 13 bus industrial distribution system.

Table 7: \% improvement of THDv when using a ML-PI controller as compared with that of a ML-PP controller

\begin{tabular}{|c|c|c|c|c|c|c|c|c|c|c|c|c|c|}
\cline { 2 - 16 } \multicolumn{1}{c|}{} & \multicolumn{10}{c|}{ Percentage improvement in THDv \% in study cases } & \multicolumn{1}{c|}{ (10 } \\
\hline Buses & $\mathbf{7}$ & $\mathbf{8}$ & $\mathbf{9}$ & $\mathbf{1 0}$ & $\mathbf{1 1}$ & $\mathbf{1 2}$ & $\mathbf{1 3}$ & $\mathbf{1 4}$ & $\mathbf{1 5}$ & $\mathbf{1 6}$ & $\mathbf{1 7}$ & $\mathbf{1 8}$ & Av\% \\
\hline $\mathbf{1 0 0}$ & 18.6 & 28.9 & 15.2 & 3.4 & 3.5 & 14.7 & 15.9 & 4.5 & 3.6 & 33.5 & -3.6 & -3.7 & $\mathbf{1 1 . 2}$ \\
\hline $\mathbf{6 9}$ & 8.7 & 26.9 & 15.5 & 3.4 & 3.3 & 10.0 & 9.7 & 3.9 & 1.1 & 33.4 & -1.9 & 1.0 & $\mathbf{9 . 6}$ \\
\hline $\mathbf{0 3}$ & 3.1 & 12.2 & 14.4 & 3.1 & -0.1 & 2.2 & 1.7 & 3.6 & 0.1 & 24.3 & -0.2 & 2.7 & $\mathbf{5 . 6}$ \\
\hline $\mathbf{5 0}$ & 3.1 & 12.9 & 14.5 & 3.1 & 6.6 & 2.2 & 1.8 & 3.6 & 0.1 & 24.6 & -0.2 & 2.7 & $\mathbf{6 . 2}$ \\
\hline $\mathbf{5 1}$ & 0.0 & 31.2 & 23.2 & 0.0 & 1.4 & 4.3 & 4.0 & 0.0 & -0.2 & 23.8 & -0.1 & -0.1 & $\mathbf{7 . 3}$ \\
\hline $\mathbf{0 5}$ & 3.1 & 12.2 & 14.4 & 3.1 & 3.3 & 2.2 & 1.7 & 3.6 & 0.1 & 24.3 & -0.2 & 2.7 & $\mathbf{5 . 9}$ \\
\hline $\mathbf{4 9}$ & 3.2 & 24.3 & 15.2 & 3.2 & 3.4 & 2.3 & 2.1 & 3.6 & 0.1 & 24.5 & -0.3 & 2.8 & $\mathbf{7 . 0}$ \\
\hline $\mathbf{3 9}$ & 3.1 & 22.1 & 15.3 & 3.2 & 3.4 & 2.2 & 1.9 & 3.6 & 0.1 & 24.2 & -0.2 & 2.8 & $\mathbf{6 . 8}$ \\
\hline $\mathbf{2 6}$ & 3.1 & 12.1 & 14.4 & 3.1 & 3.3 & 2.2 & 1.7 & 3.6 & 0.1 & 24.2 & -0.2 & 2.7 & $\mathbf{5 . 9}$ \\
\hline $\mathbf{0 6}$ & 3.1 & 12.2 & 14.4 & 3.1 & 3.3 & 2.2 & 1.7 & 3.6 & 0.1 & 24.3 & -0.2 & 2.7 & $\mathbf{5 . 9}$ \\
\hline $\mathbf{1 1}$ & -0.1 & 20.4 & 23.1 & -0.2 & -0.4 & 0.1 & -0.2 & 0.0 & -0.1 & 23.6 & -0.2 & 0.4 & $\mathbf{5 . 5}$ \\
\hline $\mathbf{1 9}$ & 3.1 & 22.0 & 15.3 & 3.2 & 3.4 & 2.2 & 1.9 & 3.6 & 0.1 & 24.2 & 3.1 & 2.8 & $\mathbf{7 . 1}$ \\
\hline $\mathbf{2 9}$ & 4.3 & 16.6 & 8.9 & 0.3 & 1.7 & 2.9 & -0.5 & 12.8 & -0.8 & 14.9 & 5.2 & 0.4 & $\mathbf{5 . 6}$
\end{tabular}

Table 8: \% improvement of THDi when using a ML-PI controller as compared with that of a ML-PP controller

\begin{tabular}{|c|c|c|c|c|c|c|c|c|c|c|c|c|c|}
\cline { 2 - 15 } \multicolumn{1}{c|}{} & \multicolumn{10}{c|}{ Percentage improvement in THDi \% in study cases } & \multicolumn{1}{c|}{ Av } \\
\hline Buses & $\mathbf{7}$ & $\mathbf{8}$ & $\mathbf{9}$ & $\mathbf{1 0}$ & $\mathbf{1 1}$ & $\mathbf{1 2}$ & $\mathbf{1 3}$ & $\mathbf{1 4}$ & $\mathbf{1 5}$ & $\mathbf{1 6}$ & $\mathbf{1 7}$ & $\mathbf{1 8}$ & Av \\
\hline $\mathbf{2 9}$ & 15.5 & 7.9 & 4.6 & 11.9 & 22.2 & 11.4 & 14.0 & 8.9 & 0.5 & 2.2 & 15.0 & 50.2 & $\mathbf{1 3 . 7}$ \\
\hline $\mathbf{2 9}$ :LL & 8.9 & 24.3 & 0.0 & 1.6 & 2.1 & 7.0 & 2.1 & 12.9 & -12.0 & 21.8 & 2.1 & 2.2 & $\mathbf{6 . 1}$ \\
\hline
\end{tabular}




\section{Analysis of the Results}

The results obtained for the PSOPI controller in tables ( $3 \& 4$ ) for the THDv\% are compared with those obtained under the DPC [9] at bus 29 and with 5\% allowable limit set by the IEEE 519-1992 [13], and the comparison are shown in table (7). The following comments are reached:

- Applying PSOPI controller improves $92.4 \%$ of THDv\% of the measred cases at all the system buses, while it improves all the average $\mathrm{THDv} \%$ at system buses.

- Applying the PSOPI filter improves and decrease the THDv\% at bus 29 in all cases except cases $13 \& 15$.

- The THDv\% at bus 29 , which is directly connected to the proposed PSOPI filter reaches 8.83 in the study case \#18 (the highest THDv\% in the measured 12 study cases) while it was 9.473 with the TPC filter and 17.77 without filter.

- The THDv\% exceeds the allowable 5\% limit by connecting PSOPI to bus 29 for $30.1 \%$ of the measurements, while it exceeds by $32.05 \%$ with DPC.

The results obtained for the PSOPI controller in tables ( $5 \& 6$ ) for the THDv\% are compared with those obtained under the DPC at bus 29 and with 5\% allowable limit set by the IEEE 519-1992 for low voltage systems in which the short-circuit current lies between 20: 50 times the load currents, and the comparison are shown in table (8). The following comments are reached:

- The THDi\% of the linear load (bus 29:LL), which is connected in parallel with the harmonic load, with PSOPI controller filter is less than the allowable limit in all the 12 study cases, while without filter it exceeds the limit in 7 cases.

- Current total harmonic distorion (THDi\%) for bus 29 $\&$ bus 29:LL are improved due to the connection of the PSOPI control scheme than with DPC in all cases except with case \#15 at bus 29:LL.

- The THDi\% at bus 29 with PSOPI filter do not exceed the 5\% allowable limit in all cases, while with DPC filter exceed the limit in five cases (cases \#8, \#10, \#13, \#16, and \#18).

- Average percentage improvement for the PSOPI filter over the DPC filter for the THDi\% at bus 29 reaches $13.7 \%$ while for the $\mathrm{THDi} \%$ at linear load connected to bus 29:LL reaches $6.1 \%$.

- The THDi\% at bus 29:LL with PSOPI filter reaches $3.048 \%$ and $2.82 \%$ in the study cases \#14 and \#15 respectivily, which are the worest two cases and less than $2 \%$ in the other 10 cases.
- The THDi\% reaches $3.7 \%$ at bus 29 in case \#18, which could be seen as the worst case at this bus. However, it should be noticed that the THDi\% at this bus was $7.52 \%$ befor adding the PSOPI filter.

\section{Conclusions}

In this paper, a new APF scheme depends on PSOPI controller, which uses two independent multilayer ANNs with shift method to estimate the fundamental voltage and current components for distribution network is introduced. The feedback signals in this paper are the per-unit values of the voltage and current with an inner inductor voltage feedback loop and an outer current feedback loop for current compensation. The proposed filter is tested and compared with the $\mathrm{DPC}$ on a 13 bus industrial distribution system and the results can summarized in the following points:

- Applying PSOPI controller improves $92.4 \%$ of THDv\% of the measred cases at all the system buses, while it improves all the average THDv\% at system buseswith respect to DPC.

- The THDi\% of the linear load (bus 29:LL), which is connected in parallel with the harmonic load, with PSOPI controller filter is less than the allowable limit in all the 12 study cases, while without filter it exceeds the limit in 7 cases.

- The THDi\% at bus 29 with PSOPI filter do not exceed the 5\% allowable limit in all cases, while with DPC filter exceed the limit in five cases (cases \#8, \#10, \#13, \#16, and \#18).

\section{References}

[1] Zainal Salam, Tan Perng Cheng and Awang Jusoh "Harmonics Mitigation Using Active Power Filter: A Technological Review" Faculty of Electrical Engineering Universiti Teknologi Malaysia, VOL. 8, NO. 2, 2006, 17-26.

[2] Djaffar Ould Abdeslam, Patrice Wira, Jean Mercklé, Damien Flieller, and Yves-André Chapuis "A Unified Artificial Neural Network Architecture for Active Power Filters" IEEE Transactions on Industrial Electronics, Vol. 54, Issue 1, pp. 61-76, February 2007

[3] Z. Lu, T. Y. Ji, W. H. Tang and Q. H. Wu "Optimal Harmonic Estimation Using A Particle Swarm Optimizer" IEEE Transactions on Power Delivery, Vol. 23, No. 2, pp. 1166-1174, April 2008.

[4] W.M. El-Mamlouk, M.A. El-Sharkawy, H. E. Mostafa, "Testing the Accuracy of ML-ANN for Harmonic Estimation in Balanced Industrial Distribution Power System" Proceeding of the (WASET) World Academy of Science, 
Engineering and Technology Conference ( International Conference on Computer, Electrical, and Systems Science, and Engineering ) Amsterdam, Netherlands, September 23-25, 2009.

[5] N. Gupta, S.P. Singh, and S.P. Dubey "Fuzzy Logic Controlled Shunt Active Power Filter for Reactive Power Compensation and Harmonic Elimination" $2^{\text {nd }}$ international conference on computer \& communication technology (ICCCT), pp. 82-87, 2011.

[6] M. Jha, and S.P. Dubey "Neuro-Fuzzy Based Controller for a Shunt Active Power Filter" International conference on power and energy (ICPE), pp. 1-7, 2011

[7] S.S. Patnaik, and A.K. Panda "Optimal Load Compensation by 3-phase 4-wire Shunt Active Power Filter Under Distortion Mains Supply Employing Bacterial Foraging Optimization" Annual IEEE India conference (INDICON), pp. 1 6, 2011 .

[8] Boluo Xie "Artificial Neural Network Based Scheme for Voltage and Harmonic Compensation" Ph.D. University of Newfoundland, Canada, December 2006.

[9] W.M. El-Mamlouk, M.A. El-Sharkawy, H. E. Mostafa, "Active Power Filter Controller for Harmonic Suppression in Industrial Distribution System" Ain Shams Engineering Journal, Vol. 2, No. 3-4, pp. 161-172, Sept.- Dec. 2011.

[10] X. Yu, X. Xiong, Y. Wu “A PSO-Based Approach to Optimal Capacitor Placement With Harmonic Distortion Consideration" Electric Power Systems Research, Vol. 71, pp. 27-33, 2004.

[11] J. Kennedy and R. Eberhart, "Swarm Intelligence”, Book, Morgan Kaufmann Publishers, 2001.

[12] B. Birge, "PSOt - a particle swarm optimization toolbox for use with Matlab" Proceedings of the IEEE Swarm Intelligence Sy mposiu m, pp. 182-186, April 2003.

[13] Task Force on Harmonic Modeling and Simu lation, Transmission \& Distribution Committee IEEE Power Engineering Society" Test Systems for Harmonics Modeling and Simulation", IEEE Transactions on Power Delivery, Vol. 14, No. 2, pp. 579-587, April 1999.

[14] Transmission \& Distribution Committee IEEE Power Engineering Society, "Test Systems for Harmonics Modeling and Simulation", IEEE Transactions on Power Delivery, Vol. 14, No. 2, April 1999.

[15] W.M. El-Mamlouk, M.A. El-Sharkawy, H. E. Mostafa, "Harmonic Currents Circulation in Electrical Networks Simulation and Analys is", $9^{\text {th }}$ IASTED Eurobean conference on Power and
Energy Systems, EuroPES 2009, Palma de Mallorca, Spain, pp 67-72, 7-9 Sept., 2009.

[16] Task Force on Harmonics Modeling and Simulation, "Modeling and Simulation of the Propagation of Harmonics in Electric Power Networks", IEEE Trans. on Power Delivery, Vol 11, No. 1, pp. 452-465, January 1996.

[17] IEEE Standard 519-1992, "IEEE recommended practice and requirements for harmonic control in electrical power systems", IEEE Industry Applications Society/Power Engineering Society, April 12, 1993.

\section{Authors' Profiles}

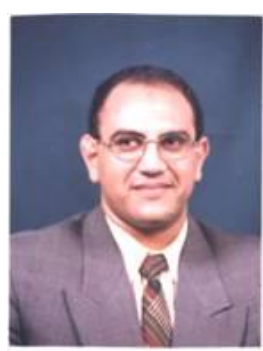

Wael M. El-Mamlouk (M'10): was born in Cairo, Egypt. He received his B.Sc. \& M. Sc. From department of electrical power and machines, Cairo university, Egypt in 1995, 2002 respectively. His Ph.D. was from depertment of electrical power and machines, Ain Shams University, Egypt 2010. He worked for Shaker Consultancy Group, Egypt as an electro-mechanical site project manager for high rises buildings in the period from 1995 to 2007 . Currently he is working for (KAHRA MAA) Qatar, as a senior electrical design reviewer engineer for mega projects. $\mathrm{He}$ is member in the IEEE, IASTED \& QGBC. His current research interests are power quality, harmonic active filters, renewable energy and electrical green building applications. His email is: welmamlouk@ieee.org.

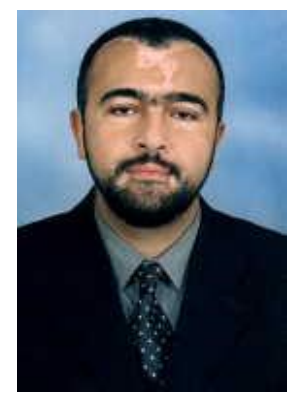

Hossam EMostafa (M'09): was born in Cairo, Egypt in 1965. He received his B. Sc, M. Sc \& $\mathrm{Ph}$. D. From Ain Shams University, Cairo, Egypt in 1987, 1994 and 1999 respectively. From 1991 to 2001, he was working in Egypt Air Company as second engineer. Since 2001, he has been a faculty member with the Electrical Department at the Faculty of Industrial Education, Suez Univ. Suez, Egypt. He is currently an Associate Professor and head of Electrical dept. He has been a visiting Prof in many universities in Kuwait, Saudi Arabia, and Egypt. His research interests are applying AI techniques in power system wide area control, protection, smart grids \& power quality. His email is: hossam.mostafa@ieee.org.

Metwally A. Elsharkawy: received his B. Sc. \& M. Sc. Degrees from the Department of Electrical Power and 
Machines, Ain Shams University, Cairo, Egypt in 1964 and 1970, respectively. He received the $\mathrm{PhD}$ degree from the Leningrad Polytechnical Institute, USSR, in 1974. Since January $1988 \mathrm{He}$ is a Prof. of Electrical Power Systems in the Electrical Power and Machines Engineering Department, Ain Shams University. He has been a visiting Prof in many universities in Iraq, and Egypt. He has more than 60 published papers in journals and conferences. He supervised about $30 \mathrm{M}$. Sc. and $\mathrm{Ph} . \mathrm{D}$. thesis (granted), mainly in analysis and control on power systems and power quality. He is registered as a Professional Engineer in the Syndicate of Egyptian engineers, and acted as an independent consultant for several electrical installations and power networks planning projects in Egypt. He was selected as a member of the Board of Directors of the Delta Company for Electricity Distribution in Egypt and occupied this position for 6 years.

How to cite this paper: Wael M. Elmamlouk, Hossam E. Mostafa, Metwally A. El-Sharkawy,"PSO-Based PI Controller for Shunt APF in Distribution Network of Multi Harmonic Sources", International Journal of Intelligent Systems and Applications(IJISA), vol.5, no.8, pp.54-66, 2013. DOI: 10.5815/ijisa.2013.08.07 